\title{
Sulfur isotope fractionation during incorporation of sulfur nucleophiles into organic compounds $\dagger$
}

\author{
Alon Amrani, ${ }^{a}{ }^{a}$ Qisheng Ma, ${ }^{a}$ Ward Said Ahmad, ${ }^{b}$ Zeev Aizenshtat ${ }^{b}$ and Yongchun Tang ${ }^{a}$ \\ Received (in Cambridge, UK) 5th November 2007, Accepted 2nd January 2008 \\ First published as an Advance Article on the web 16th January 2008 \\ DOI: $10.1039 / b 717113 g$
}

\begin{abstract}
${ }^{34} \mathrm{~S}$ enrichment is shown to occur during sulfurization reactions and for the first time conclusively attributed to an isotope equilibrium effect rather than selective addition of ${ }^{34} \mathrm{~S}$ enriched nucleophiles.
\end{abstract}

Reactions between sulfur nucleophiles and functionalized organic compounds under aqueous conditions play significant roles in the chemical industry, environmental science, chemical biology and geochemistry. ${ }^{1-4}$ Although the mechanisms of the formation of the sulfurized products were studied, no attention was given to changes in the natural abundance, stable isotope ratio $\left({ }^{34} \mathrm{~S} /{ }^{32} \mathrm{~S}\right)$ accompanying these reactions. These isotopic changes are very small, not detectable by regular MS, but they can give an important insight into the mechanism and reaction pathways without the need for isotopic enrichment or the use of radioisotopes. In the present work we study these ${ }^{34} \mathrm{~S} /{ }^{32} \mathrm{~S}$ ratio changes, taking advantage on recent developments in methodology and instrumentation that enable highly accurate and reliable isotopic measurements of $\mathrm{S}$ employing continuous flow isotope ratio mass spectrometry (CF-IRMS). For convenience, the ${ }^{34} \mathrm{~S} /{ }^{32} \mathrm{~S}$ changes are depicted as a permil (\%) deviation from the standard V-CDT (Vienna Canyon Diablo Troilite) using the $\delta$ notation according to eqn (1):

$$
\begin{aligned}
\delta^{34} \mathrm{~S}= & {\left[\left(R_{\text {sample }} / R_{\text {standard }}\right)-1\right] 1000 \%, } \\
& \text { Where } R=\left[{ }^{34} \mathrm{~S}\right] /\left[{ }^{32} \mathrm{~S}\right] .
\end{aligned}
$$

Sulfur isotope fractionation during the reaction of polysulfide anions $\left(\mathrm{S}_{x}{ }^{2-}\right)$ and organic model compounds was recently investigated. ${ }^{5}$ That study showed that the reaction of $\mathrm{S}_{x}{ }^{2-}$ with carbonyl compounds results in $a{ }^{34} \mathrm{~S}$ enrichment of the products of $4-5 \%$ at equilibrium. However, this study assumed that the very complex $\mathrm{S}_{x}{ }^{2-}$ solution is isotopically homogenous and that there is no ${ }^{34} \mathrm{~S}$ enrichment of the $\mathrm{S}_{x}{ }^{2-}$ as compared with $\mathrm{H}_{2} \mathrm{~S} / \mathrm{HS}^{-}$in the same solution. A recent study challenges this assumption by showing that $\mathrm{S}_{x}{ }^{2-}$ are indeed ${ }^{34} \mathrm{~S}$ enriched by up to $6 \%$ as compared with $\mathrm{H}_{2} \mathrm{~S} / \mathrm{HS}^{-}$ and by $3.4 \%$ compared with total $\mathrm{S}$ in solution. ${ }^{6}$ These findings raised the possibility that the observed ${ }^{34} \mathrm{~S}$ enrichment of the organic sulfur compounds is not due to ${ }^{34} \mathrm{~S}$ enrichment

\footnotetext{
${ }^{a}$ Chemistry and Chemical Engineering Division, California Institute of Technology,CA 91125, USA. E-mail: aamrani@caltech.edu; Fax: 626-683-0621; Tel: 626-395-6271

${ }^{b}$ The Chemistry Institute, Hebrew University, 91904 Jerusalem, Israel $\dagger$ Electronic supplementary information (ESI) available: Experimental and molecular modeling procedures, optimized coordinates for all structures, supplementary data for Tables 1-3, GC-MS trace for some of the products. See DOI: $10.1039 / \mathrm{b} 717113 \mathrm{~g}$
}

during the addition of sulfur into organic matter but rather to selective addition of $\mathrm{S}_{x}{ }^{2-}$ into the aldehydes. This view is supported by the much higher reactivity of $\mathrm{S}_{x}{ }^{2-}$ as compared with $\mathrm{H}_{2} \mathrm{~S} / \mathrm{HS}^{-}$.

In order to distinguish between these two possible mechanisms, we reacted aldehydes and haloalkanes in aqueous solutions of $\mathrm{CH}_{3} \mathrm{SH}$ or $\mathrm{H}_{2} \mathrm{~S}$ at $\mathrm{pH}=8-9$ at $25^{\circ} \mathrm{C}$. The reaction with $\mathrm{CH}_{3} \mathrm{SH}$ cannot form $\mathrm{S}_{x}{ }^{2-}$. Therefore any isotope effects can be attributed to the formation of $\mathrm{C}-\mathrm{S}$ bonds and measure its $\delta^{34} \mathrm{~S}$ without the bias of $\mathrm{S}_{x}{ }^{2-}$ fractionation. The reaction with $\mathrm{H}_{2} \mathrm{~S}$ was carried out anaerobically to prevent oxidation of $\mathrm{H}_{2} \mathrm{~S}$ and formation of $\mathrm{S}_{x}{ }^{2-}$. In each reaction an aliquot of the solution was injected into a $\mathrm{AgNO}_{3} / \mathrm{NH}_{4} \mathrm{OH}$ solution to precipitate $\mathrm{Ag}_{2} \mathrm{~S}$ for $\delta^{34} \mathrm{~S}$ analysis to set the initial $\mathrm{H}_{2} \mathrm{~S} / \mathrm{HS}^{-}$ value.

The results in Table 1 show that the incorporation of $\mathrm{CH}_{3} \mathrm{SH}$ yields a ${ }^{34} \mathrm{~S}$ enrichment of the reaction products of $3.1-5.4 \%$. The main products from the reaction with the saturated aldehydes were the gem disulfide or the Michael addition adducts in the case of the $\alpha, \beta$-unsaturated aldehydes. It is interesting to note that the ${ }^{34} \mathrm{~S}$ enrichments measured for the conjugated addition into 2-octenal were lower than the saturated carbonyl addition. The reaction of $\mathrm{H}_{2} \mathrm{~S} / \mathrm{HS}^{-}$with saturated aldehydes yielded the gem-dithiols and their disulfide analogues as the major products and the Michael addition adducts with 2 -octenal. The ${ }^{34} \mathrm{~S}$ enrichment ranged between 4.5 and $8.1 \%$. Again, products of the reactions with saturated aldehydes were more ${ }^{34} \mathrm{~S}$ enriched than were those from conjugated unsaturated aldehydes (Table 1). These results

Table 1 Experimental measurements of ${ }^{34} \mathrm{~S}$ enrichment (\%o) in sulfurized products of reactions between $\mathrm{S}$ nucleophiles and organic substrates under aqueous conditions. Measurement error $\pm 0.3 \%$ o

\begin{tabular}{llc}
\hline Precursor & $\mathrm{Reactant}$ method $^{a}$ & $\Delta^{34} \mathrm{~S}(\%)$ \\
\hline Citral $\left(+\mathrm{NH}_{4} \mathrm{Cl}\right)$ & $\mathrm{CH}_{3} \mathrm{SH}$ & 3.7 \\
Citral & $\mathrm{CH}_{3} \mathrm{SH}$ & 3.1 \\
trans-Oct-2-enal & $\mathrm{CH}_{3} \mathrm{SH}$ & 3.5 \\
Octanal $\left(+\mathrm{NH}_{4} \mathrm{Cl}\right)$ & $\mathrm{CH}_{3} \mathrm{SH}$ & 4.4 \\
Octanal & $\mathrm{CH}_{3} \mathrm{SH}$ & 5.4 \\
trans-Oct-2-enal & $\mathrm{HS}^{-} / \mathrm{A}$ & 4.8 \\
Butanal & $\mathrm{HS}^{-} / \mathrm{A}$ & 7.3 \\
trans-Oct-2-enal & $\mathrm{HS}^{-} / \mathrm{B}$ & 4.5 \\
trans-Hepta-2,4-dienal & $\mathrm{HS}^{-} / \mathrm{B}$ & 4.8 \\
Octanal & $\mathrm{HS}^{-} / \mathrm{B}$ & 7.1 \\
Butanal & $\mathrm{HS}^{-} / \mathrm{B}$ & 8.1 \\
1-Bromobutane & $\mathrm{HS}^{-} / \mathrm{B}$ & -2.5 \\
${ }^{a}$ See ESI $\dagger$ for detailed method description. \\
\hline
\end{tabular}


demonstrate an equilibrium isotope effect since the sulfurized products are ${ }^{34} \mathrm{~S}$ enriched.

In addition to the experimental approach, we applied firstprinciple quantum mechanics calculations to estimate the magnitude of equilibrium isotope effect. Traditionally, the equilibrium constant of an isotope exchange reaction could be calculated using the so-called Urey model or Bigeleisen and Mayer equation, both of which require measured vibrational frequencies as inputs. ${ }^{7,8}$ However, such experimental data are not always available, or may contain large uncertainties. In the present study, we use density functional theory (DFT) as an $a b$ initio method to predict normal mode vibrational frequencies and the standard thermodynamic calculations to evaluate the Gibbs' free energies and the equilibrium constant of the isotopically substituted compound. The relation between the isotopic changes and the Gibbs' free energy difference of compounds containing either ${ }^{34} \mathrm{~S}$ or ${ }^{32} \mathrm{~S}$ is given by eqn (2):

$$
\Delta\left(\delta^{34} \mathrm{~S}_{\mathrm{A}}-\delta^{34} \mathrm{~S}_{\mathrm{B}}\right)=1000\left(\mathrm{e}^{-\Delta G / R T}-1\right)
$$

where $\mathrm{A}$ and $\mathrm{B}$ are the compounds undergoing isotopic exchange according to eqn (3):

$$
{ }^{34} \mathrm{~A}+\mathrm{B}=\mathrm{A}+{ }^{34} \mathrm{~B}
$$

An important issue in using the adequate methodology is the requirement for very high accuracy of the calculated Gibbs' free energies, since the isotopologues differ in $\Delta G$ only slightly. Most currently available computational software packages generate $\Delta G$ values with $\sim 1.0 \mathrm{cal} \mathrm{mol}^{-1}$ accuracy and are not sufficient to distinguish at the level of $0.1 \%$. Therefore, we used the standard thermodynamics theory ${ }^{9}$ to recalculate the individual terms of the Gibbs' free energy at higher accuracy using a MATLAB program. We have calculated several known products of the $\mathrm{MeSH}$ and $\mathrm{H}_{2} \mathrm{~S}$ addition to aldehydes, some of which are intermediate structures. Isotope effects were calculated for each of these structures independently. The isotopic measurements reported here reflect an average $\mathrm{S}$ isotopic value for the bulk organic extract. To date, there is no compound specific isotope measurement method with the accuracy needed for $\delta^{34} \mathrm{~S}$ changes.

The calculated values (Table 2) compared very well for the conjugated additions (such as Michael addition) with the experimental results of $\mathrm{HS}^{-}$addition (Table 1). In the case of saturated aldehydes, experimental data are closer to modeled isotope effect for intermediate compounds (thioaldehyde and ene-thiols) than the final products. This may give a hint to the reaction pathway as suggested in previous studies, ${ }^{10,11}$ because it is expected that most of the isotopic exchange will occur during formation of the more chemically labile intermediates (Scheme 1). The more stable end products (i.e. saturated thiols) equilibrate very slowly with the surrounding $\mathrm{S}$ pool at our experimental temperature. Therefore, the experimental data presented in Table 1 reflect mainly the fractionations associated with formation of these intermediates and are higher than the calculated values for the end products. When comparing the modeling and experimental data it is important to note that the ionic nucleophiles $\left(\mathrm{HS}^{-}\right.$and $\mathrm{MeS}^{-}$), as well as the different conformations of the sulfurized products may have different fractionation factors, for simplicity, we only
Table 2 Molecular modeling prediction of the ${ }^{34}$ S enrichment (\%o) of $\mathrm{S}$ containing molecules in equilibrium with $\mathrm{S}$ nucleophiles at $20^{\circ} \mathrm{C}$

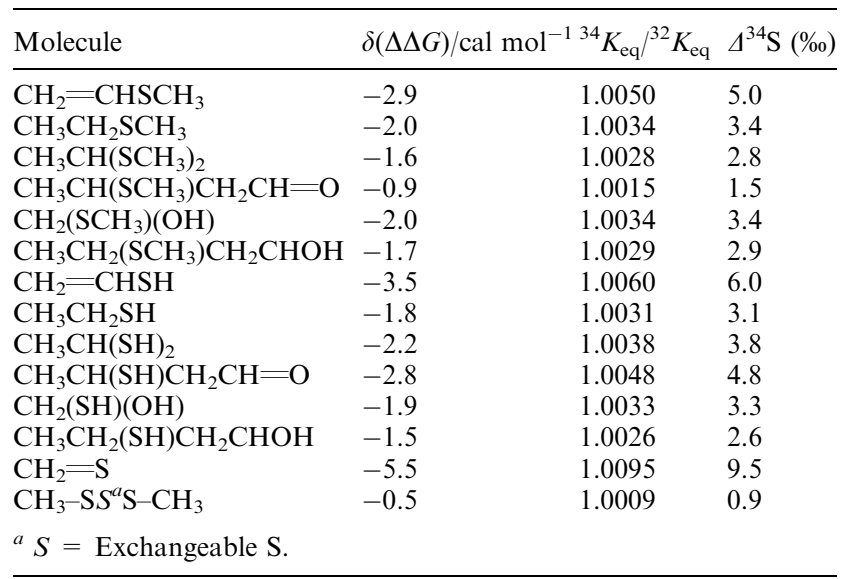

consider the neutral species and the most energetically favourable conformations i.e. anti or trans (see optimized coordinates in ESI $\dagger$ ). For example, the fractionation between $\mathrm{HS}^{-}$and $\mathrm{H}_{2} \mathrm{~S}$ is reported to be $2-2.7 \%$. ${ }^{12}$ Our experimental $\mathrm{pH}$ causes the $\mathrm{HS}^{-}$to be predominant nucleophile hence, the total calculated fractionation between $\mathrm{HS}^{-}$and the sulfurized adducts (Table 2) may be higher by $2-2.7 \%$ and thus will be closer to the observed experimental data (Table 1). These experiments and theoretical considerations show that the enrichment observed in aldehyde adducts is related to the $\mathrm{C}-\mathrm{S}$ bond formation followed by isotopic exchange. This is in agreement with previous study on the addition of sulfite into carbonyls. $^{13}$

To compare our results with a reaction that is not reversible we used 1-bromobutane that forms the corresponding 1butanethiol via an $\mathrm{S}_{\mathrm{N}} 2$ mechanism, under the same experimental conditions. The thiol was depleted in ${ }^{34} \mathrm{~S}$ by $2.5 \%$ supporting the isotopic kinetic effect (KIE) mechanism. Because the mechanism is irreversible, and the product (thiol) equilibrates very slowly with the $\mathrm{H}_{2} \mathrm{~S}$ solution, ${ }^{14}$ the KIE imprint will preserve under our experimental conditions.

In our previous study, the $\delta^{34} \mathrm{~S}$ value of thiol from the reaction between haloalkanes and $\mathrm{S}_{x}{ }^{2-}$ was between 0 and $1 \%$ rather than ${ }^{34} \mathrm{~S}$ depleted as in the present study. ${ }^{5} \mathrm{~A}$ possible explanation for this is the formation of polysulfides bonds

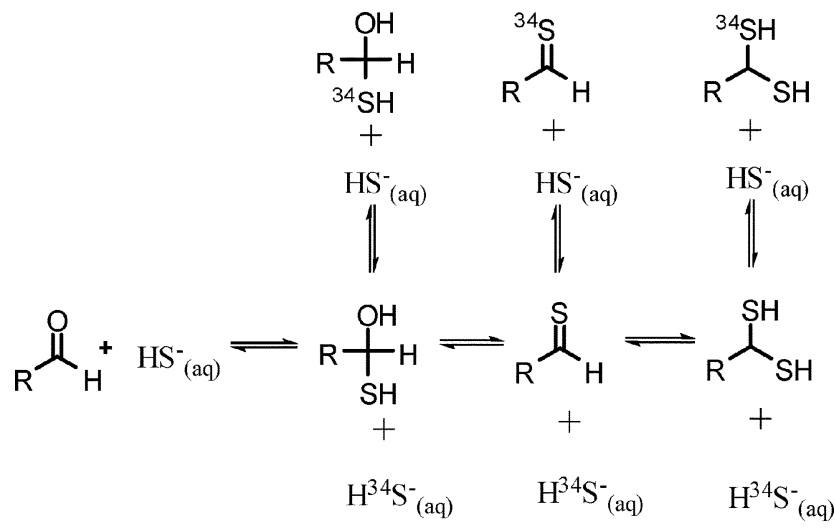

Scheme 1 Suggested pathway for reaction of aldehydes with $\mathrm{HS}^{-}$and accompanying isotopic exchange. 
Table 3 Experimental measurements of ${ }^{34} \mathrm{~S}$ enrichment (\%o) in the sulfurized products of the reactions between $\mathrm{S}_{x}{ }^{2-}$ and organic substrates under PTC conditions (toluene/water). Measurement error $\pm 0.3 \%$

\begin{tabular}{llll}
\hline Precursor & Reactant & Method $^{a}$ & $4^{34} \mathrm{~S}(\%)$ \\
\hline Citral & $\left(\mathrm{NH}_{4}\right)_{2} \mathrm{~S}_{x}$ & Water & 4.4 \\
Citral & $\left(\mathrm{NH}_{4}\right)_{2} \mathrm{~S}_{x}$ & PTC & 6.1 \\
Geranyl bromide & $\left(\mathrm{NH}_{4}\right)_{2} \mathrm{~S}_{x}$ & Water & 1.1 \\
Geranyl bromide & $\left(\mathrm{NH}_{4}\right)_{2} \mathrm{~S}_{x}$ & PTC & 3.8 \\
1,2-Dibromohexane & $\left(\mathrm{NH}_{4}\right)_{2} \mathrm{~S}_{x}$ & Water & 0.1 \\
1,2-Dibromohexane & $\left(\mathrm{NH}_{4}\right)_{2} \mathrm{~S}_{x}$ & PTC & 2.3 \\
1-Chlorooctane & $\left(\mathrm{NH}_{4}\right)_{2} \mathrm{~S}_{x}$ & Water-methanol & 1.0 \\
1-Chlorooctane & $\left(\mathrm{NH}_{4}\right)_{2} \mathrm{~S}_{x}$ & PTC & 3.4 \\
${ }^{a}$ See ESI file for detailed method description. & \\
\hline
\end{tabular}

rather than thiol or disulfides, which through isotopic equilibrium with $\mathrm{S}-\mathrm{S}$ bonds were $\delta^{34} \mathrm{~S}$ enriched. ${ }^{15}$ We have calculated this value to be around $1 \%$ (Table 2) which is not large enough to explain this isotopic difference. A more likely mechanism is the selective addition of ${ }^{34} \mathrm{~S}$ enriched $\mathrm{S}_{x}{ }^{2-}$ that are known to be much stronger nucleophiles than $\mathrm{H}_{2} \mathrm{~S} / \mathrm{HS}^{-}{ }^{2}$

In order to further demonstrate a selective addition mechanism of ${ }^{34} \mathrm{~S}$ enriched $\mathrm{S}_{x}{ }^{2-}$, we performed several experiments employing a phase transfer catalysis (PTC) system. PTC is a bi-phasic organic/aqueous system (toluene/water) in which the $\mathrm{S}_{x}{ }^{2-}$ can selectively transfer into the organic phase and react with the organic substrate. ${ }^{16}$ We observed an additional ${ }^{34} \mathrm{~S}$ enrichment of $1.7-2.7 \%$ in the reaction of all model compounds (aldehydes and haloalkanes) with $\mathrm{S}_{x}{ }^{2-}$ under PTC conditions as compared with aqueous conditions. ${ }^{5}$ Table 3 compares the $\delta^{34} \mathrm{~S}$ results obtained from reactions performed under PTC and aqueous conditions. The sulfurization of bromoalkanes by $\mathrm{S}_{x}{ }^{2-}$ results in enrichment of $0.1-1.1 \%$ under aqueous conditions and $2.3-3.8 \%$ under PTC conditions. Citral showed similar trend of ${ }^{34} \mathrm{~S}$ enrichment using the PTC method. The products of these reactions consist mainly of polysulfide dimers or polymers. ${ }^{1}$ The tertiary ammonium that acts as a PTC (dimethyldidecylammonium bromide) is suggested to selectively extract the $\mathrm{S}_{6}{ }^{2-}$ and transfer it to the organic phase where the reaction with the model compounds can take place. ${ }^{16,17}$ Since $\mathrm{S}_{x}{ }^{2-}$ are ${ }^{34} \mathrm{~S}$ enriched compared with total $\mathrm{S}$ species in solution by up to $3.4 \%$ (as a function of their chain length) ${ }^{6}$ the organic phase will be ${ }^{34} \mathrm{~S}$ enriched. The sulfurized products in the organic phase are not in direct contact with the aqueous $\mathrm{S}_{x}{ }^{2-}$ solution and the isotopic mixing and exchange is limited to $\mathrm{S}_{x}{ }^{2-}$ that transfers into the organic phase. Therefore, it is likely that the isotope exchange following formation of the $\mathrm{C}-\mathrm{S}$ bond involves $\mathrm{S}$ that is already in the organic solution. The sulfur isotopic composition of the products reflects the $\delta^{34} \mathrm{~S}$ of the transferred $\mathrm{S}_{x}{ }^{2-}$ plus the additional ${ }^{34} \mathrm{~S}$ enrichment resulting from equilibrium isotope effects. In the case of the KIE mechanism, such as in the case of bromoalkanes, $\delta^{34} \mathrm{~S}$ values mostly reflect the value of the ${ }^{34} \mathrm{~S}$ enriched $\mathrm{S}_{x}{ }^{2-}$.

In conclusion, this study shows for the first time that the ${ }^{34} \mathrm{~S}$ enrichment of products formed by sulfurization of aldehydes is caused by formation of $\mathrm{C}-\mathrm{S}$ bonds and is not a result of selective incorporation of $\mathrm{S}_{x}{ }^{2-}$ enriched in ${ }^{34} \mathrm{~S}$. Selective incorporation of ${ }^{34} \mathrm{~S}$-enriched $\mathrm{S}_{x}{ }^{2-}$ is shown to occur in PTC systems and to a lesser extent, in the formation of organic polysulfides from halogenated compounds in aqueous solutions. The suggested mechanism is thermodynamic equilibrium between the $\mathrm{S}$ nucleophiles and the organic $\mathrm{S}$ as supported by both experimental and theoretical approaches. The extent of the resulting ${ }^{34} \mathrm{~S}$ enrichment is dependent on the functionality of the reactive molecule. The results of this study will help explain the isotopic differences that are often observed in natural samples of marine and wetlands environments between coexisting organic and inorganic $\mathrm{S}$ species. Moreover, this study points to the promising potential for the natural abundance of $\mathrm{S}$ stable isotopes ratio changes as a tool for the interpretation of reactions mechanisms between sulfur nucleophiles and functionalized organic compounds.

The authors wish to thank David Sprinzak (Caltech) for help with MATLAB programing and Alex Sessions (Caltech) and Dmitri Gelman (Hebrew University) for helpful comments and discussions on an earlier version of this paper.

\section{Notes and references}

1 A. Amrani and Z. Aizenshtat, Org. Geochem., 2004, 35, 909.

2 A. R. Loch, K. A. Lippa, D. L. Carlson, Y. P. Chin, S. J. Traina and A. L. Roberts, Environ. Sci. Technol., 2002, 36, 4065-4073.

3 B. L. Shi and M. F. Greaney, Chem. Commun., 2005, 886-888.

4 N. S. Krishnaveni, K. Surendra and K. R. Rao, Chem. Commun., 2005, 669-671.

5 A. Amrani and Z. Aizenshtat, Org. Geochem., 2004, 35, 1319.

6 A. Amrani, A. Kamyshny, O. Lev and Z. Aizenshtat, Inorg. Chem., 2006, 45, 1427.

7 J. Bigeleisen and M. G. Mayer, J. Chem. Phys., 1947, 15, 261-267.

8 H. C. Urey, J. Chem. Soc., 1947, 562-581.

9 D. A. McQuarrie and J. D. Simon, Molecular Thermodynamics, University Science Books, Sausolito, CA, 1999.

10 A. Amrani, J. W. Turner, Q. S. Ma, Y. C. Tang and P. G. Hatcher, Geochim. Cosmochim. Acta, 2007, 71, 4141-4160.

11 P. Schneckenburger, P. Adam and P. Albrecht, Tetrahedron Lett., 1998, 39, 447-450.

12 B. Fry, H. Gest and J. M. Hayes, Chem. Geol., 1986, 58, 253-258.

13 W. A. Sheppard and A. N. Bourns, Can. J. Chem., 1954, 32, 4-13.

14 A. Amrani, W. Said-Ahamed, M. D. Lewan and Z. Aizenshtat, Geochim. Cosmochim. Acta, 2006, 70, 5146-5161.

15 H. Sakai, J. Inorg. Nucl. Chem., 1966, 28, 1567.

16 E. B. Krein and Z. Aizenshtat, J. Org. Chem., 1993, 58, 6103-6108.

17 R. G. Teller, L. J. Krause and R. C. Haushalter, Inorg. Chem., 1983, 22, 1809-1812. 